\title{
Geotechnical analysis of the stability and the seepage for an artificial energy atoll close to the Belgian coast
}

\author{
Herman Peiffer ${ }^{1}$ \\ ${ }^{1}$ Ghent University, Ghent, BELGIUM (herman.peiffer@ugent.be)
}

\begin{abstract}
The subject of this work is to analyze the behavior and stability of the dams of an energy atoll. A study of the site conditions of the Northsea was done in order to get a general layout of the problem. The study focuses on the achievement of a reduction of the seepage and the impermeability of the dams. Step by step, an optimal concept of the dam is obtained by investigating different solutions for different problems such as seepage, slope stability, bearing capacity and feasibility. The different failure mechanisms are analyzed based on a parametric analysis and using a numerical model. Different concept proposals are proposed and evaluated.
\end{abstract}

Keywords: Renewable energy, offshore, dam stability, energy storage

\section{Introduction}

The increasing production of green energy, for example produced by wind turbines in a sea farm, can result in a disturbance of the balance between production and consumption of electricity. This can cause blackouts and decreases the value of renewable energy. Therefore it is important to investigate the possibility of the use of the energy in times of overproduction for storing a capacity of energy in a sea atoll, in a way that this energy can be used in times of a higher demand of energy. The possibility of an energy atoll in the North Sea close to the Belgian coast has been investigated. An atoll is a torus shaped, offshore dam where water can be pumped out to store energy. The energy can be regenerated when the water flows back in the atoll through turbines. In this work, in particular the stability and seepage problem of such an energy atoll is analyzed.. The objective is to obtain a design which fulfills the needs of an atoll. This article is also based on the results of the numerical analysis done by Peeraer [1]

\section{Methodology}

\subsection{Site conditions}

The foundation of the dam is important for its stability. The Northsea consists of a thick tertiary (clay) layer with a quaternary layer on top of it [2] [3]. This quaternary layer can consist of a variety of soil types. It is beneficial to build an offshore structure like an atoll on a sandbank because of the shallower water. Because of this, the toplayer will consist of sand. Investigations done by several authors results in the characteristics of the soil layers found in the Northsea.[4] [5]. 
The design of an offshore construction is in an important way based on the wave characteristics. With the assumption of an economical livespan of 50 years and a chance of $5 \%$ that the construction will fail during this livespan, the significant wavehight Hs can be set to $6.92 \mathrm{~m}$ at the Northsea [6]. During the storm described by a Hs of $6.92 \mathrm{~m}$, there will be a raise of the waterlevel of $6.9 \mathrm{~m}$. Incorparating the fact that the sea level will rise during the first 50 years due to climate change about $22 \mathrm{~cm} \mathrm{[7],}$ the high water level (HW) is situated at $4.51 \mathrm{mTAW}$, the low water level (LW) at $0.73 \mathrm{mTAW}$ and during the design storm the water level will be $7.20 \mathrm{mTAW}$ [8] [6]. There are two extreme water level situations: HW at sea (4.51mTAW) and LW in the atoll (-15mTAW) and LW at sea (0.73mTAW) and HW in the atoll (4.51mTAW). Together with the starting situation there are three water level situations that are being investigated.

\subsection{Analysis using the Finite Element Method}

The numerical analysis is done by the 2D finite element package PLAXIS (release 8). The factor of safety is calculated by the $\varphi^{\prime}-c^{\prime}$ - reduction' procedure. It is defined as the ratio of the available shear strength to the shear strength at failure by summing the incremental multiplier $\left(\mathrm{M}_{\mathrm{sf}}\right)$.

Because of the high economical risk of this project, a FS of 1.5 needs to be obtained [9].

The soils are described by constitutive models. In this project two models are used: the Mohr-Coulomb model (MC) and the Hardening Soil model (HS).

The MC-model is a linear elastic, perfect plastic model which uses the MC-failure criterion with c' and $\varphi$ ' respectively the effective cohesion and the effective friction angle. The advantage of the MC-model is its simplicity. The prediction of the soil behavior based on the MC-model will result in a first estimation. Also in case no detailed information of the soil characteristics (strength, stiffness) is available, this model is applied.

$$
\tau_{f}=c^{\prime}+\sigma_{n \cdot}^{\prime} \tan \left(\varphi^{\prime}\right)
$$

The HS-model, as described and verified by Schanz et al. [6] and Brinkgreve (2002) [10], also uses the MC-failure criterion but takes hardening in account.

In the HS-model the stiffness is well defined and the use of the model will result in a better prediction of soil behavior.

The problem is that a lot more input variables have to be known in order to use this model (instead of the MC-model). In this study the use of the HS-model is important for the foundation layers. For these layers the necessary soil characteristics were available.

\subsection{Description of the design model}

\section{Foundation}

Based on soil investigations done in the Northsea, there is enough information available to model the subsoil with the HS-model. This results in more realistic re- 
sults. Because it is not possible to do oedometer or triaxial tests on rubble and concrete armour units, there is no information available to model these with the HSmodel. Consequently, these materials are modelled with the MC-model.

Starting from the literature [3], the following layered soil profile of the Northsea can be made:

The first (upper) layer is a sand layer which represents the sandbank and has a thickness of about $20 \mathrm{~m}$. The second layer is also about $20 \mathrm{~m}$ thick and represents the other quaternary deposits (sandy clay). The lowest relevant layer (starting from $55 \mathrm{mTAW}$ ) is the tertiary clay layer. In table I, an overview of the soil characteristics is presented. For this analysis, three different sand types are considered to model the upper layer (A). Again, three different types of soil are taken into account to model the second layer (B). For this layer, the parameters vary from those of a clayey material (B1) to those of a sandy material (B3). The last layer (C) is modelled as clay.

\section{Parameters subsoil}

By combining these soil models, 9 profiles of the subsoil are investigated. Three types for top layer (sand) combined with three types for the sandy clay layer (varying from clay to sand) and an underlying clay layer.

Table 1. soil characteristics.

\begin{tabular}{llllllll}
\hline unit & $\begin{array}{l}\text { Soil depth } \\
\text { from .. to }\end{array}$ & $\varphi^{\prime}$ & $\mathrm{c}^{\prime}$ & $\mathrm{m}$ & $\begin{array}{l}\text { Eoed, ref } \\
(\mathrm{kPa}))\end{array}$ & $\begin{array}{l}v \\
(-)\end{array}$ & $\begin{array}{l}\mathrm{k} \\
(\mathrm{m} / \mathrm{s})\end{array}$ \\
\hline A.1 & $-15 \mathrm{~m}-\mathrm{-} 35 \mathrm{~m}$ & 30 & 1 & 0.7 & 20 & 0.3 & $1^{\mathrm{e}}-04$ \\
A.2 & & 32.5 & & 0.6 & 30 & & \\
A.3 & & 35 & & 0.55 & 65 & & \\
\hline & & 20 & 8 & 0.95 & 5 & 0.5 & $1^{\mathrm{e}-06}$ \\
B.1 & $-35 \mathrm{~m}-55 \mathrm{~m}$ & & & & & & \\
B.2 & & 25 & 4 & 0.75 & 7 & 0.5 & \\
B.3 & & 30 & 1 & 0.65 & 12 & 0.3 & \\
\hline C.1 & $-55 \mathrm{~m}-\ldots$ & 20 & 10 & 0.95 & 9 & 0.5 & $1^{\mathrm{e}-09}$ \\
\hline
\end{tabular}

\section{Breakwater layout}

Starting from the knowledge of designing a breakwater using the wave characteristics of the site, a first layout is designed. This is done according to the Coastal Engineering Manual (CEM) [11]. The result is a breakwater with a slope 3/1 as displayed in figure 1. It is important to remark that an excavation of $10 \mathrm{~m}$ is made at the inside of the dam to increase the capacity of the atoll.

\subsection{Parameter study}

A dam layout as a breakwater is not an ideal solution for an atoll because it is made up by rubble and thus it is very permeable. Because the permeability of the dam de- 
fines how much energy can be stored, this structure needs to have a very low permeability.

Considering high sea level (4.51mTAW (TAW = National Topographic Reference Level in Belgium ('Tweede Algemene Waterpassing')) and a low waterlevel in the atoll $(-15 \mathrm{mTAW})$, the maximum flow through the dam of the atoll is $1.23 \mathrm{E}+05 \mathrm{~m}^{3} / \mathrm{s}$ when the dams have a breakwater layout as presented in figure 1 . This is about $1 \%$ of the total volume per second and thus much too high.

Because there is an excavation at the inside of the atoll, it would be economically very interesting to reuse this sand in the dam. Using a sandcore (with some modifications in order to get a sufficient stability) would be ideal to reduce the permeability. Unfortunately it is impossible to make offshore slopes of sand between $1 / 3$ and 1/2. A solution to this problem is to work with cofferdams of rubble and a sandfill in between. To keep the sand separated from the rubble, geotextiles can be used. This layout is represented in figure 2 with a slope of $3 / 1$.

\section{Seepage}

The influence of the new layout on the seepage is significant because of the lower permeability of the sand in the core. The maximum flow decreases to $48.05 \mathrm{~m} 3 / \mathrm{s}$ which is $23.53 \%$ of the total volume per day. To lower the permeability even more, it is possible to add a geomembrane to the dam. This geomembrane can be placed at different positions. The positions that are investigated are (A) at the seaside of the dam (at the inside of the cofferdam), (B) central in the dam and (C) and on both sides of the dam.

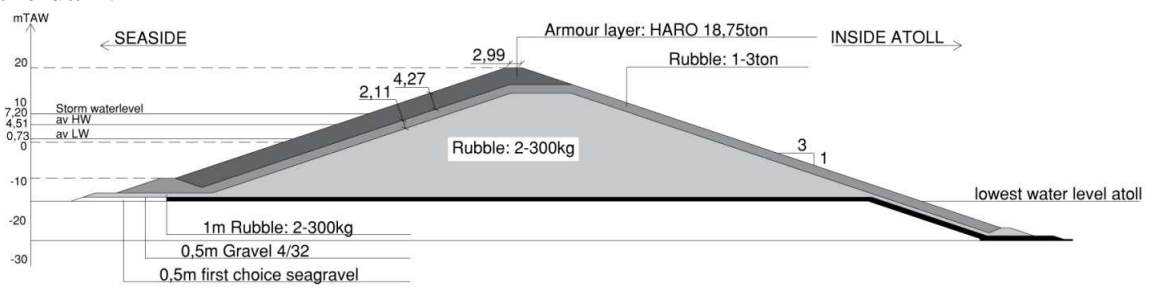

Fig. 1. Dam layout as breakwater.

The geomembranes results in a significant reduction of seepage. The obtained percentages are respectively $7.27 \%$ (option A), $18.56 \%$ (option B) and $4.10 \%$ (option C) of the total volume per day. For options $\mathrm{A}$ and $\mathrm{C}$ in figure 3 , the decrease in seepage is most significant. Because the technical feasibility of option B is low, together with higher flow through the dam, this option is not further investigated. Although a seepage of $7.27 \%$ or $4.10 \%$ is still higher than the limit as given by the British Standard, these percentages correspond to the efficiency of the turbines, which is about $90 \%$ to $95 \%$.

It can be concluded that seepage can be lowered significantly by using cofferdams and geomembranes and that acceptable percentages of seepage can be obtained. 


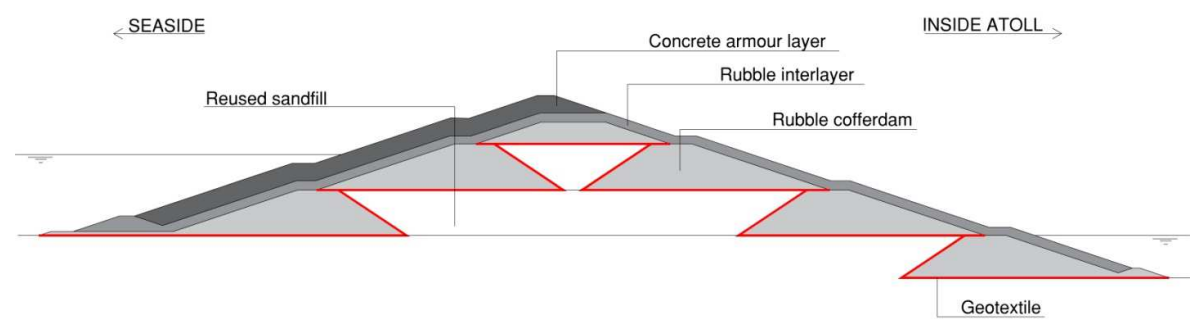

Fig. 2. Illustration of a dam layout with cofferdams.

Stability - influence of the placement of a geomembrane on the stability of the dam

Out of this analysis it could be found that that the FS increases with about $13 \%$ for the most dangerous situation of levels of water (HW-LW) when a geomembrane is placed at seaside. With this solution, all the subsoils satisfy the desired FS of 1.5. On the other hand, a geomembrane placed at both sides resulted in a decrease of the safety factor.

The increase of the FS as a result of the geomembrane can be used to obtain a more economical design by steepening the slopes. It can be concluded that a geomembrane has two advantages: besides the reduction of seepage, the safety factor increases for all subsoils in the situation HW-LW.

Steepening the slope results in an average decrease of 0.2 in FS from $3 / 1$ to $5 / 2$ and from $5 / 2$ to $2 / 1$. The slope $2 / 1$ was too steep for all situations. In general a slope of $5 / 2$ was safe enough. 11. For the subsoils 231, 321 and 331, there was still some room for optimization of the slope steepness. Therefore, a slope of 9/4 was additionally investigated for these combinations.

The results are displayed in the right column of table III. It can be seen that the FS is high enough for all situations. It can be concluded that this slope is optimal for these subsoils.

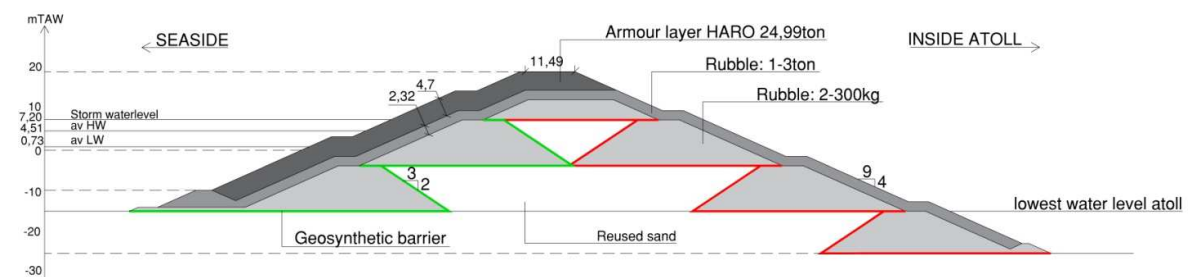

Fig. 3. Dam layout with a slope $9 / 4$

\section{CONCLUSION}

Starting from the design of a breakwater, the dam layout was adapted to fulfill the needs for the dams of an atoll. Using a construction with cofferdams offers the opportunity to reuse the sand that is excavated. Furthermore, the permeability decreases because of this sand. A geomembrane is added at the seaside of the dam to lower the 
permeability even more and improve the stability in the most critical situation (high water at sea and low water in the atoll). To lower the percentage of seepage and to minimize material costs, the slopes are steepened as much as possible for every subsoil. A slope 5/2 is the optimal slope for subsoils 121, 131 and 311. A slope $9 / 4$ for the subsoils 221, 231, 321 and 331. In table $\mathrm{V}$, an overview is presented for every investigated subsoil Also, the percentage of seepage is given in this table.

Table 2. Overview of the factors of safety (slope stability) per subsoil.

\begin{tabular}{llll}
\hline Subsoil & Slope & Lowest FS & $\begin{array}{l}\text { Seepage } \\
(\% \text { volume/day })\end{array}$ \\
\hline 121 & $5 / 2$ & 1.55 & 5.45 \\
\hline 131 & $5 / 2$ & 1.58 & 5.45 \\
\hline 221 & $9 / 4$ & 1.56 & 5.17 \\
\hline 231 & $9 / 4$ & 1.58 & 5.17 \\
\hline 311 & $5 / 2$ & 1.52 & 5.45 \\
\hline 321 & $9 / 4$ & 1.61 & 5.17 \\
\hline 331 & $9 / 4$ & 1.62 & 5.17 \\
\hline
\end{tabular}

\section{References}

1. S. Peeraer "Numerical Analysis of the Stability and behavior of an artificial energy atoll at the Belgian coast", master thesis, 2014

2. S. Le Bot, V. Van Lancker, S. Deleu, M. De Batist, and J. Henriet, Tertiary and Quaternary Geology of the Belgian Continental Shelf. PPS Science policy, 2003.

3. H. J.P. and D. M. G., Eds., The Quaternary and Tertiary Geology of the Southern Bight, North Sea. Ministry of Economic Affairs - Belgian Geological Survey, 1989.

4. C. Surarak, S. Likitlersuang, D. Wanatowski, A. Balasubramaniam, E. Oh, and H. Guan, "Stiffness and strength parameters for hardening soil model of soft and stiff bankok clays," Soils and foundations, vol. 52,pp. p.682-697, 2012.

5. T. Schanz, P. Vermeer, and P. Bonnier, "The hardening soil model: Formulation and verification," in Beyond 2000 in Computational Geotechnics 10 Years of PLAXIS, Rotterdam, 1999.

6. http://www.vlaamsehydrografie.be/hydrometeoatlas.htm[Online]Available:http://www.v laamsehydrografie.be/hydrometeoatlas.htm

7. J. De Ronde, P. Heinen, H. Middelkoop, J. Oerlemans, and C. Schuurmans, "De keerzijde van ons klimaat," 1998.

8. IMDC, Hydraulisch ranvoorwaardenboek Vlaamse kust. Ministerie van de Vlaamse Gemeenschap. Departement Leefmilieu en Infrastructuur.Administratie Waterwegen en Zeewezen. Afdeling Waterwegen Kust, 2005.

9. Geotechnical Manual For Slopes, Geotechnical Engineering Office, 1984.

10. R. Brinkgreve, "Plaxis finite element code for soil and rock analysis,"PLAXIS, Rotterdam, Tech. Rep. version 8, 2002.

11. Coastal Engineering Manual, 3rd ed., US Army Corps of Engineers, September 2011. 